\title{
Cellular Differentiation Assessment
}

National Cancer Institute

\section{Source}

National Cancer Institute. Cellular Differentiation Assessment. NCI Thesaurus. Code C132430.

The determination of the amount of cellular differentiation in a biological sample. 